\title{
FRANCISCO DE CONTRERAS Y EL NAUFRAGIO DE SEPULVEDA
}

A Eugenio Asensio

Al abordar una vez más un tema estrechamente relacionado con el naufragio de Sepúlveda, no me queda otro remedio que referirme a éste, aunque sea brevemente y repita conceptos ya vertidos en otro lugar, y lo hago a fin de poner en antecedentes a aquellos lectores que no conozcan esta dramática historia y la importancia que tuvo su expresión literaria.

Los frecuentes naufragios de naves portuguesas que hacian la ruta de la India - los había también en la ruta americana- dieron lugar en Portugal, durante los siglos xvI y xvIr, a una literatura popular que recogia en pliegos de cordel las relaciones de algunos de los más sonados de aquellos desastres. En el siglo xvirr, un coleccionista de estos folletos, Bernardo Gomes de Brito, publicó unos cuantos con el sugestivo título de História Trágico-Maritima ${ }^{1}$, título que ha pasado a designar a esta clase de relatos. Entre ellos destaca el que recoge el naufragio de Sepúlveda, sin duda alguna el más difundido y el de mayor resonancia literaria ${ }^{2}$.

1 História Trdgico-Marltima em que se escrevem chronologicamente os Naufrdgios que tiverão as Naos de Portugal, depois que se poz em exercicio a Navegacáo da India, 2 tomos, Lisboa, I735-1736.

- Relafia da muy notduel perda do galeão grande S. Jodo, em que se contao os grandes trabalhos e lastimosas cousas que acontecerdo ao capitao Manoel de Sousa Sepúlveda e o lamentdvel fim que elle e sua mulher e filhos, e toda a mais gente, houverão na Terra do Natal, onde se perderdo a 24 de Junho de 1552, en ob. cit., I, pp. I-38.

Anteriores a la edición de Gomes de Brito, por la que cito, se conservan cuatro de Lisboa, I564, 1592, I625 y 1633, y una de Evora, 1614. La primera edición, hoy desconocida, apareció hacia 1555. Véase J. Duffy, Shipwreck and Empire, Harvard Uniwersity Press, Cambridge Mass., 1955, y C. R. Boxer, "An introduction to the Histbria Tragico-Marttiman, en Rev. da Faculdade de Letras, Lisboa, III serie, núm. I, 1957, pp. 48-99. 
Según la Relação anónima, el galeón S. João, fletado por el capitán Manuel de Sousa Sepúlveda, partió de Cochin el 3 de febrero de r552, llevando a bordo, además de la familia de Sepúlveda - doña Leonor de Sá, su esposa, dos hijos de corta edad habidos en el matrimonio y otro de más años, fruto de un devaneo del capitán-, una numerosa tripulación, entre marinería y esclavos, y un pesado cargamento de especiería y otras mercancías, producto de sus ganancias en Asia, y con las que pensaba negociar en Lisboa. Tras dos meses de navegación, el galeón fue destruido por una tempestad a la altura de la costa de Natal. La mayor parte de los tripulantes y pasajeros consiguieron llegar a tierra, donde se organizaron y emprendieron una penosa marcha en busca del río de Lourenço Marques, con la esperanza de encontrar allí alguna nave portuguesa de comerciantes de marfil y llegar así a Portugal. Durante el camino, el hambre, la sed, los cafres y las fieras van diezmando al grupo. El hijo natural de Sepúlveda es una de las víctimas. Más tarde son acogidos por un régulo cafre que les ayuda y previene de los peligros que les esperan si siguen adelante. Sepúlveda desoye estas advertencias y no tardan en caer en la trampa que les tiende otro régulo; son entonces despojados de todo lo que todavía poseen, incluso la ropa que llevan puesta. En esta situación, Leonor oculta su desnudez cubriéndose con los cabellos y la arena de una playa. Sepúlveda va a la selva en busca de alimentos, pero cuando regresa encuentra muertos a Leonor y sus dos hijos; los entierra en la playa y después se interna para siempre en la selva.

Aparte de su éxito popular, esta historia, que dejó también eco en los cronistas de la expansión portuguesa en Asia, atrajo desde muy pronto a los poetas; en primer lugar a los portugueses, después a los españoles, y aun trascendió a otros países europeos ${ }^{1}$.

En Portugal explotaron la veta, con más o menos extensión y fortuna, Camões, en un breve pero justo pasaje de Os Lusiadas (Lisboa, I572, V, 46-48), Luís Pereira Brandão, que recogió el suceso en el canto VI de su prosaico poema Elegiada (Lisboa, 1588) y Jerónimo Corte Real, que le consagró un farragoso, aunque no despreciable poema

1 Para un conocimiento más completo del tema, véase ROBERTo BARQUIESI, "Os Sucessos de Sepúlveda. Tragedia portoghese del xvmr secolo", en Annali dell' Istituto Universitario Orientale, XVII, 2, 1975, pp. 229-239; id., "Un tema portoghese: il naufragio di Sepúlveda e la sua diffusionen, en id., XVIII, 2, 1976, pp. 193-23I; Jos ARES MONTES, "I resti di un naufragio", en Quaderni portoghesi 5. 1979 (en prensa). 
compuesto de I7 cantos, Naufrágio de Sepuilveda (Lisboa, I594) ${ }^{1}$. En España, Lope de Vega recordó la tragedia en un pasaje de la silva III del Laurel de Apolo (1630), además de la comedia, si es suya, de Don Manuel de Sosa y naufragio prodigioso, y del principe trocado (probablemente, según la Cronología de Morley y Bruerton, de I598-1600) $y$, en fin, pero no el último, Tirso de Molina, que escenificó los sucesos en la mediocre comedia Escarmientos para el cuerdo (hacia I624, publ. en la Quinta Parte de sus comedias, Madrid, 1636).

A esta nada despreciable aportación española al tema, hay que añadir un poema conocido hasta ahora sólo por el título y sus características bibliográficas, y citado siempre, por los que lo citan sin haberlo visto, como simple traducción del poema de Corte Real. Me refiero a la Nave trágica de la India de Portugal, de Francisco de Contreras ${ }^{2}$, cuya descripción bibliográfica creo que se publicó por primera vez en I866, en el Ensayo de una biblioteca de libros raros y curiosos, de Bartolomé José Gallardo (II, núm. I88I) ${ }^{3}$.

Fue sin duda Nicolás Antonio el primero que se refirió al autor y su obra en la Bibliotheca Hispana Nova (Roma, 1672), donde dice -cito por la ed. de Madrid, I783, I, 4I6-: «Franciscus de Contreras, Hispano carmine miserrimum Emmanuelis Sousae, Lusitani Equitis, naufragium cecinit, quod argumentum Hieronymus Cortealis vernaculo prius luserat Portugalliae metro, scilicet: Nave Trágica de la India de Portugal. 1624.4. Matritin. Es más que probable que tomase de aquí la referencia Diogo Barbosa Machado para su Bibliotheca Lusitana, donde, al tratar del poema de Corte Real, en el artículo correspondiente

1 Naufragio e lastimoso sucesso da perdiçam de Manoel de Sousa de Sepúlveda e Dona Lianor de Sd su molher e filhos, vindo da India para este Reyno na nao chamada o galião grande $S$. João que se perdeo no cabo de boa Esperanfa na terra do Natal. E a peregrinafia que tiverdo rodeando terras de Cafres mais de 300 legoas té sua morte. Compasto em verso heroico e octava rima por JERónIMO CORTE REAL. Dirigido ao excelentíssimo principe D. Theodósio Duque de Bragança e Barcellos, Marques de Vilaviçosa, Conde de Ourem, Senhor das Villas d'Arrayollos e Portel. Summa felicidade. Com licença da Sancta Inquisição e do ordinário e de sua Magestade. Na oficina de Simão Lopez. Com privilégio Real por dez annos. M.D.XCIIII. 4 h. +206 fs.

- Nave trdgica de la India de Portugal, por Francisco DE CONTrERAs, natural de Argamasilla de Alba. A Lope Félix de Vega Carpio, Fiscal de la Cámara Apostólica. Con licencia. En Madrid, por Luis Sánchez, affo de $1624,3 \mathrm{~h} .+18 \mathrm{fs}$.

- Manuel Alvar vio el ejemplar existente en la Biblioteca de la Hispanic Society de Nueva York, pues copia la décima de Lope de Vega en elogio del autor. Véase "Cinco papeletas bibliográficas sobre Lope de Vega", en Rev. de Filologia Española, XIVI, 1963, pp. 45I-458; la referencia en la pág. 456. 
a este autor, dice: "Foy traduzida [esta obra] em Castelhano em Outava rima por Francisco de Contreras com o nome de Nave Trágica da India de Portugal. Madrid. I624.4. Dedicado a Lopo de Vega Carpio» ${ }^{1}$.

Notemos, sin embargo, que Barbosa añade algo más: que el poema de Contreras está escrito en octava rima, que está dedicado a Lope de Vega y, en fin, que es traducción del poema de Corte Real. Las precisiones sobre el tipo de estrofa y la dedicatoria hacen pensar que Barbosa tuvo en sus manos un ejemplar de la Nave trágica o que alguien le dio esos datos. Pero ¿y la traducción? ¿Procede también de un informador? ¿Ha llegado Barbosa a esta conclusión tras la lectura, muy dudosa, del poema español, o ha interpretado mal las palabras de Nicolás Antonio? El bibliógrafo español se limita a decir que Contreras cantó en verso español el tema que anteriormente había cantado Corte Real en verso portugués. Pero la suerte estaba echada: a partir de la afirmación de Barbosa se ha venido repitiendo lo mismo por quienes pudieron confrontar los dos poemas y no lo hicieron, y por quienes no pudiendo hacerlo, lo afirmaron; otros lo han dejado en un interrogante. He aquí algunos hitos de esta trayectoria: en 1846, partiendo de Barbosa, como él mismo dice, George Ticknor vuelve a afirmar que el poema de Corte Real "fue... traducido al castellano por Francisco de Contreras con el título de "Nave trágica de la India de Portugal", I624" ${ }^{2}$. En Portugal, Inocêncio Francisco da Silva certifica -su fuente es, por supuesto, Barbosa-: "Sahiu também traduzido em oitavas castelhanas por Francisco de Contreras, que o deu à luz em Madrid, I624, 4. ${ }^{\circ}{ }^{3}$. Cejador, aceptándolo siempre como traducción, precisa algo más: "poema en cien octavas y tres cantos" ". Roberto Barchiesi dice, al tratar del poema portugúes: «i bibliografi citano una traduzione spagnola ad opera di Francisco de Contreras (Nave trágica de la India de Portugal, Madrid, 1624) che sarebbe stata dedicata a Lope de Vegan ${ }^{5}$. $Y$ Frank Pierce, deduciéndolo sin duda de las dimensiones del poema portugués y de las que Cejador da del español, puesto que confiesa no haber visto todavía éste, matiza su referencia al sugerir que se trata

1 Bibliotheca Lusitana, II, Lisboa, I747, p. 497.

- Cito por la traducción española, Historia de la Literatura Española, III, Madrid, 1854, p. 173, n. 12 .

s Artículo Jerónimo Corte Real, en Dicciondrio Bibliogrdphico Portugwez, III, Lisboa, 1859, p. 262.

- Historia de la Lengua y Literatura castellana, V, Madrid, 1916, p. 35.

- "Un tema portoghese: il naufragio di Sepúlveda e la sua diffusione», p. 200, nota. 
de una utraducción abreviada» ${ }^{1}$. ¿Para qué seguir por este camino? Felizmente, la Nave trágica no se ha hundido del todo $\mathrm{y}$, aparte los ejemplares que existen en bibliotecas extranjeras (en la de la Hispanic Society y en el British Museum), la Biblioteca Nacional de Madrid posee una (R-Varios I63-I3) que ha servido de base a este trabajo ${ }^{2}$.

Pero antes de entrar en el estudio de este poema, ¿sabemos algo acerca de su autor? Francisco de Contreras, el hombre, es un arcano. Desde la portada y preliminares de su poema hasta hoy nada nuevo se ha descubierto sobre su identidad. Era natural de Argamasilla de Alba, villa manchega de resonancias cervantinas, amigo y admirador de Lope de Vega, probablemente también protegido. A él dedica la Nave trágica en retóricos términos marinos muy en consonancia con el tema del poema, donde el mar es el elemento desencadenante de la tragedia. Así, dirá que se embarca uen piélagos de dificultades, solicitando sobresaltos y tempestades" y que arrostra "las olas de diversidad de pareceres", aunque al "considerar que los que miran fixo y luziente norte, llegan a deseado puerto, y que si yo no perdía de vista al que fue siempre tan fixo en toda erudición, como luziente en agudeza y aplauso, como es el ingenio de v. m.n, es de esperar que alcance también éxito en su carrera; y termina expresando su deseo de "que este mi pequeño trabajo no aparte los ojos de la luz que, qual estrella, le ha de guiar hasta darle dichoso puerto en las manos de la protección de v. m., a quien el cielo prospere en todo largos años». Lope, como Fiscal de la Cámara Apostólica, firma la aprobación del libro "que es - dice- verdadero sucesso de que hablan las historias de Portugal, a quien imita en versos y estilo digno de mayores años». Después, le dedica una décima laudatoria:

La nave que a Portugal
dio llanto en vez de tesoro,
Contreras con lineas de oro
buelve en Argos celestial;
oy, como el ave imperial,
la sube en plumas tan bellas,
que atrevida al sol con ellas
trágica dexa de ser,
que su ingenio pudo hazer
todos sus versos estrellas

1 La poesia épica del Siglo de Oro, 2.* ed., Madrid, 1968, p. 349.

- Una vez más expreso públicamente mi gratitud al profesor Eugenio Asensio, quien me habla facilitado anteriormente una fotocopla de dicho ejemplar.

- Reproduzco los textos sin más modificaciones que los camblos ortográficos $\mathfrak{u}=\boldsymbol{v}, \nabla=\mathfrak{u}$, deshacer abreviaturas, regularizar el uso de mayrisculas $\mathbf{y}$ modernizar acentos y puntuación. 
Junto a Lope, dedican también versos elogiosos al poema y al autor -recogidos todos en los preliminares del libro- otros poetas: cultas décimas de Tirso de Molina, D. Rodrigo de Galiana, D. Luis Ferreira, D. José de Samano y D. Pedro de Ypenarieta, y un soneto anónimo "de un amigo», que llama "divir.o joven" al autor. Sí, Contreras debía ser muy joven en ese momento, como parece desprenderse también de las palabras de Lope citadas más arriba: «estilo digno de mayores años».

De Contreras se conocen seis composiciones más de menor categoría que la Nave trágica. Cinco, en loor de Polonia, fueron publicadas en los preliminares del libro de Matías Titlevuski, Relación diaria de las guerras tenidas entre Polacos y Turcos por los años I620 y I62I (Madrid, I623): dos madrigales a "Segismundo, Rey de Polonia", por sus triunfos frente a la kabatida y medrosa" luna turca, un soneto "al Sereníssimo Príncipe Vladislao", dos décimas "a las insignias del Rey de Polonia», y otro madrigal "a la Nación Polaca». Son poesias ocasionales, retóricas, altisonantes, cultas, que bien podrían calificarse de ejercicios poéticos. La sexta composición es un "Gratulabundum carmen. Hispaniorum regi pro sucepto Principe», publicado en el libro de Cristóbal de Lazarraga, Fiestas de la Universidad de Salamanca al nacimiento del Principe D. Baltasar Carlos..., (Salamanca, I630, pp. 188-89).

La Nave trágica es, aparte su argumento, un típico producto de la poesía narrativa española del primer tercio del siglo xvir; poesía narrativa levemente matizada con elementos líricos, con preferencias por la fábula mitológica o la combinación de la mitologia con la historia, como ocurre en el poema de Contreras, y a cuyo cultivo debió contribuir en no pequeña medida, aparte ilustres ejemplos del siglo XVI, el perfecto logro artístico del Polifemo gongorino. Justamente, la huella de Góngora se descubre en más de una octava de la Nave trágica. Y no me refiero sólo al léxico, porque en el momento en que Contreras escribe su poema, el léxico cultista, usado intensamente por el poeta cordobés, ha pasado al dominio público de la poesia peninsular, sin que, por tanto, se pueda afirmar siempre si tal poeta lo ha tomado directamente de la obra gongorina o si ha descendido sobre él como maná mostrenco. En nuestro caso no hay que atribuirlo todo al maná, sino a la influencia directa de Góngora.

Si bien Contreras es comedido en el uso de bimembres, además bastante grises, muestra, en cambio, ejemplos más interesantes del empleo de hipérbatos, trueque de atributos, verbo ser con el significado de 'servir', la fórmula A, si no B, perffrasis, alusiones, imágenes complejas $y$, sobre todo, un léxico culto, no muy rico - las repeticiones 
abundan, aun en una misma octava-, pero si usado intensamente, y que creo es un reflejo, con todo lo demás, de la lengua poética gongorina.

Pero la Nave trágica, y no siempre por estas imágenes o lo culto del lenguaje, resulta un poema oscuro y hasta, a veces, incomprensible para quien no esté en antecedentes de la historia de Manuel de Sousa Sepúlveda. Quizá este defecto pueda achacarse en parte a las limitaciones del propio poeta, aunque las más veces se explica por la tremenda condensación a que ha sometido los sucesos y a su expresión elíptica. Existe también un evidente desequilibrio en el tratamiento de la historia, al dedicar mayor número de octavas a un episodio en perjuicio de otros tan importantes como él o silenciándolos. La prueba más escandalosa de este desequilibrio la tenemos en que Contreras emplea los dos primeros cantos del poema en describir la tempestad y el naufragio del galeón, mientras confina en el canto tercero el resto de la historia, que es más rico en episodios que los sucesos del mar.

Esto nos lleva a comparar la Nave trágica con el Naufrágio de Sepuilveda, de Corte Real, y ver si aquélla es realmente una traducción de éste o simplemente un punto de partida bien beneficiado. $Y$ desde ahora me atrevo ya a afirmar que no estamos ante una traducción, sino ante una versión del tema expuesto con otro ritmo narrativo y otro lenguaje poético, una versión que intenta ser nueva y personal, en la medida en que puede serlo una historia que cuenta ya con antecedentes literarios inesquivables. ¿Que Contreras resume a Corte Real y a veces depende de él más de la cuenta? No sólo no lo dudo, sino que lo demostraré, como demostraré también que tuvo presente la Relação anónima. Es probable que conociese la Elegiada, de Pereira Brandão, pero cuya lectura, si la hubo, no dejó huellas visibles en nuestro poeta. Probablemente, conoció también la Década Sexta de Asia (Lisboa, 16r4), de Diogo do Couto, en cuyo libro VII, capitulo II, se hace un resumen de la historia de Manuel de Sousa, siguiendo en su mayor parte la versión de la Relação. ¿Cómo extrañarnos de una práctica corriente en aquellos tiempos? Igual que tantos poetas - tal el propio Corte Real con respecto a Garcila 0 y Camões, por no citar ahora otras fuentes-, Contreras podria decir como el francés: "Je prends mon bien où je le trouven.

En primer lugar, la Nave tragica consta de roo octavas reales, en total 800 versos, repartidas en tres cantos $(38,2 I$ y $4 I$, respectivamente). E1 Naufrágio de Sepuilveda está compuesto de I7 cantos en endecasilabos sueltos, con pasajes de tono lírico en octava rima y tercetos encadenados; en total, ro.457 versos. Corte Real, hiperbólico y acumulativo, 
envuelve la historia de Manuel de Sousa, hasta ahogarla en más de una ocasión, en una espesa red de elementos mitológicos, símbolos y alegorías. Contreras, ¿qué otra cosa podía hacer un poeta de su tiempo?, también echa mano de la mitología, pero sólo como motivo ornamental, nunca determinante, $y$ sin permitir en ningún momento protagonismo a ninguna deidad marina o terrestre, como ocurre en el poema portugués, donde Amor consigue de Venus la eliminación física de un rival amoroso de Sepúlveda y donde también Proteo, Pan y Febo arden por doña Leonor.

Corte Real inicia su poema con la proposición de regla, sigue una invocación a Jesucristo y comienza la historia con una larga relación de los amores y bodas de Leonor y Manuel, coloreado todo con curiosas notas exóticas, reflejo de la experiencia índica del autor (canto I a comienzo del V). Nada de esto existe en el poema de Contreras, cuyas tres primeras octavas, a modo de proposición, son un lamento a cuenta de la versatilidad de la fortuna. Tras un breve elogio de la estirpe noble de Manuel y Leonor, el poeta se duele que ambos esposos truequen "la muda tierra por el mar sonante», cambio infausto que será causa de irreparables males. A partir de la octava 7 (Contreras no numera las octavas, por tanto, f. 2 r.), empieza la historia con la descripción de la nave surta en el puerto de Cochin:

Cubre en su seno de Cochin el puerto una nave sobervia a quien los montes ofrecieron tributo de concierto, formando el sol mayores horizontes; talando bosques con acero yerto, materia dio a su espalda el fiero Brontes, y es tal, que menosprecia su grandeza el más fuerte castillo o fortaleza.

En lo más alto puesta, la tendida vela el cierço bate ya, Favonio popa; el ave regia que su nido vela de los altos peñascos en la copa, de do mirando el cevo se desvela, su buelo envidia quando da en la popa la vida y el aliento de la nave, que es paz en la agua y en los vientos ave.

La caterva naval el vaso ocupa y sus senos los frutos del Oriente, a los quales entrega la chalupa o el esquife a la turba de la gente. 
De todo cada qual se desocupa para hazer su viaje felizmente: todo lo entregan a la infiel carina, origen de su muerte y de su ruina.

(I, f. 2 r. $\mathrm{y}$ v.)

Corte Real había escrito con el mismo motivo los siguientes versos, cuyos ecos resuenan en los que acabo de citar:

Aparelha-se a nao, igual a hum monte, do que à navegação hé necessário, e a grão concavidade do admirável ventre occupão de fina especiaria.

A gente destinada a morte horrenda, a triste cruel fin já condenada, com alvoroço vai. Quem saber pode o que Deos só consigo determina? No grosso masto já se ve subida, lá no mais alto, a vella atravesada, ve-se quasi nas nuves tremolando a soberba bandeira solta aos ares.

(V, f. 56 r.)

I a partida de la nave está descrita moderadamente por Corte Real, él tan proclive siempre a las acumulaciones verbales:

já do patrão nos ares soa o vivo apito e a pesada áncora levão.

Deixão-se vir abaixo as despregadas vellas e segue-as logo huma alta grita, incha-se o grande treu, a nao com força as ondas rompe $e$ faz leda viage.

Con vella inchada val a nao cortando o transparente campo de Neptuno, impellida por Zéphiro, atrás deira hum rasto de salgada branca escuma. Foge-lhe a conhecida terra, fogem num momento a grão praya, o porto, a gente; altas, frondosas árvores, de vista se perdem já e em névoa se convertem

(VI, fs. 57 V.-58 r.) 
Contreras, que precisa que Sepúlveda parte "en el mes más avaro», es decir, en febrero, escaso en días, deja trasparentar en la partida de la nave la vaga silueta de los versos citados:

Zarpa la nave con sobervia pompa, varriendo plata la carina corba, al punto que sonó la hueca trompa; el zéfiro sonoro el lienço acorba, haze Neptuno que cristales rompa, quitando la tardança que le estorva, muestra al camino el plateado campo, de blanca espuma desflorando el campo.

(f. 3 r.)

$Y$ mientras Corte Real va indicando en una lenta enumeración las tierras que desde la nave se ven o adivinan, Contreras recurre a la comparsería mitológica en sus juegos marinos:

Las Nereides no temen a la noche, ni Glauco enluta su dorada arena, hazen de conchas transparente coche, viendo siempre al aurora tan serena; quita a su gruta el peñascoso broche Tritón, para que salga su sirena, con voz y mano acompañando al harpa, cuando la nave con Leonora çarpa.

Con júbilos y juegos hazen flestas anegando la plata en los cristales, procuran imitar en las florestas los juegos de briosos animales; trillan las sendas de argentadas cuestas, manchándolas con purpura y corales; la nave todo el coro solemniza y, por más festejarla, el mar eriza.

Qual plantas andaluzes generosas bien regidas en campo escaramuçan, assi las hijas de Diana hermosas con no menor destreza corren, cruçan; hazen sus ebras de oro más preciosas con las hijas del nácar, de se abuçan, y aun el roxo esplendor de sus guedejas o es invidia del sol, sino son quexas. 
En estas tres octavas - aparte los ecos gongorinos detectables- 1 , Contreras se ha sentido sin duda cautivado por la deslumbrante mascarada acuática a que recurre Corte Real - libando una vez más en Os Lusiadas - en el episodio en que Proteo, pastoreando las focas de Neptuno, descubre a Leonor y se enamora de ella:

As outras Nimphas vão todas contentes, humas de azuis e verdes ricos trajos, outras de cor dourada, outras de cores diversas variadas e apraziveis.

As fermosas Nereidas com estranha e suave armonia vão tocando músicos instrumentos... Levantão-se no mar por todas partes os estranhos sequaces de Neptuno, huns tocão conchas vãs, outros mil saltos com alegria dão nas claras ondas.

(VI, fs. 64 V.-65 r.)

Estalla la tempestad. A las I7 octavas que Contreras emplea en el canto I en describirla y lamentar sus estragos, llega un rumor de olas y vientos que evidentemente procede del poema portugués:

Cobre-se o ceo de grossas negras nuves, os ventos mais e mais cada hora crecem

Já nas pontas de mil fragosas serras a nao se mostra alçada, e já sumida em valles profundissimos, parece cobrir-se de altos montes de água grossa.

$$
\text { (VII, f. } 75 \text { r. } y \text { v.) }
$$

Y el español:

Los cielos se escurecen y encapotan con nubes negras y con ceño horrendo

Preflados montes de aguas y collados

la nave suben al obscuro cielo, de all al profundo baxan anegados, hallando una agua en otra instable suelo...

(fs. 4 v. -5 r.)

1 Iérico, la fórmula A, ai no en B en el final de la tercera octava, y la huella polifémica de "Alll una alta roca / mordaza es a una gruta de su bocan, en la octava primera. 
Junto a esto, Contreras resume en dos octavas enumerativas lo que él mismo y, sobre todo, Corte Real dilatan en largas tiradas endecasilabas:

Soplan, hieren, açotan, suben, bajan, acometen, porfian, entran, cruzan, buelcan, trastornan, hunden, quiebran, rajan, amedrentan, afligen, despeluzan; desbaratan, quebrantan, cortan, tajan, despedaçan, deshazen, desmenuzan, suenan, resuenan, braman, gimen, laten, buelven, rebuelven, corren, buelan, baten.

Señores, capitanes, siervos, tropa, indios, pilotos, pérsicos, grumetes, rarcias, amures, cables, proa, popa, bordes, gumenas, mástiles, trinquetes; perlas, zafiros, nácar, lienço, ropa, velas, vanderas, gavias, gallardetes, sondas, antenas, árboles, timones, áncoras, plaças, armas, espolones.

$Y$ vuelve a sacar al escenario, en ropaje gongorino, a las ninfas del mar empavorecidas por el desastre:

Espantadas las hijas de Nereo, el transparente nácar de su pluma a las bóvedas ondas del Letheo dirigieron, peinando undosa espuma; vomitan las alcobas de Tipheo de globos blancos numerosa suma, que son las lenguas de espumosas olas que audaces lamen las fulgurantes bolas.

\section{(f. 6 r.)}

La nave, en tanto, vomita de su vientre - una vez más este verbolas riquezas en él almacenadas, sepultándolas en "urna cristalina". Contreras aprovecha la ocasión, como frecuentemente hace Corte Real, fieles ambos a la tradición épica de la comparación como función exornadora, para deslizar esta imagen cetrera:

No assd la garça del nebll seguida, por más aligerar el presto buelo -depósito sagrado de su vida-. quando camina al açulado velo. 
vomita de su pecho la comida que le impide subir al alto cielo, como la nave, que persigue el viento, arroja de su seno su alimento.

\section{(f. 7 r.)}

Corte Real remata la descripción del naufragio en el canto VII, miestras que Contreras, que, por supuesto, es más parco en el número de versos que le consagra, prolonga la agonía de la nave a lo largo de todo el canto II de su poema. A pesar de la brevedad de este canto, Contreras se deja arrastrar por la magia de las palabras sonoras, que, como espumosas olas gongorinas, invaden a veces la trágica situación, tal en el siguiente pasaje de amanecida radiante, en que los vientos parecen dar treguas a la desarbolada nave:

Carroça de christal, ruedas de plata con cercos de coral y de oro rayos, en campos de çafiros y escarlata tiravan potros roxos, potros bayos; cuyo término en tanto se dilata en quanto de la luz los diestros ayos los limites definen, quando llora por ser vencida la rosada Aurora.

Con que al punto el Ciclope cristalino, con solo un ojo de su bella frente, al espejo bañó de cristal fino, émulo en todo de su luz ardiente: era mar celestial, cielo marino compuesto de materia diferente, ya con dos ojos que eran dos fanales engastados en cuencas de cristales.

(II, fs. 8 v. -9 r.)

Pero el viento vuelve a encrespar las olas, dificulta el salvamento de Leonor y sus hijos, que luchan uen breve esquife" por ganar la costa. En ese momento:

Salió Tritón, y con su cuerpo de oro por las soberbias olas echó un bando, que acaten de Eleonora la belleza, y al punto abaran todas la cabeça.

$$
\text { (f. } 10 \mathrm{r} \text {.) }
$$


Sin embargo, la tempestad reanuda sus ataques:

Con todo, entre los riscos de cristales

-si bien robó la Parca a muchos juntos-.

salieron otros vivos con señales

que acompañaron tristes los difuntos...

$$
\text { (f. I I r.) }
$$

Corte Real ha descrito este episodio del salvamento al final del canto VII, empleando el VIII en relatar el comienzo de las vicisitudes de los náufragos en tierra, desde el primer encuentro con un grupo de cafres y los infructuosos tratos para conseguir alimentos, hasta que deciden ponerse en camino en busca del río Lourenço Marques.

Pocas octavas le quedan a Contreras -sólo las 4I del canto IIIpara contar la larga y penosa marcha de Sepúlveda y los suyos a través de la Cafrería hasta el trágico desenlace. Sucede así que, mientras en la Relação anónima, y aun en el poema de Corte Real, a pesar de que en él todo es desmesurado, podemos seguir gradual y detalladamente el desarrollo de aquella aventura, en la Nave trágica estamos ante una rápida y confusa exposición de donde han desaparecido varios pormenores importantes para una clara comprensión del drama. Menciona, sí, por ejemplo, las andas construidas con restos del naufragio en que, privilegiadamente, será llevada Leonor por los esclavos:

Naufragantes reliquias, que a la orilla en saliva espumosa el mar ayrado ha escupido $y$, apenas ser de hastilla, entre tantos contrarios han guardado, fueron breve materia de una silla que a Leonora el respeto ha dedicado, mas fue hombro ageno breve, empresa larga de si misma, a si fue precisa carga.

$$
\text { (III, f. II v.) }
$$

El hambre y la sed atormentan a los caminantes, los diezman:

Reduxo a estremo tal en tiempo breve la esquivez de la tierra el vastimento, que aunque el hado infeliz desdichas llueve, la sed no halla en la pluvia su alimento;

fue tal el ayuno que pasaron, que leves muchos a su Dios bolaron.

(f. 12 r.) 
Las penalidades de la marcha se expresan en Contreras más por la escenografía barroca del paisaje, que por los sufrimientos de los náufragos - «muertos caminan», dice el poeta-, lo cual no ocurre ni en la Relação ni en Corte Real, donde se determinan bien esos sufrimientos ${ }^{1}$ :

Eran alli las breñas y peñascos sobervias atalayas de su alteza, do el cielo se pudiera abrir los cascos a no aver levantado la cabeça; de horrendas grutas son tela y damascos selvática esquivez, horror, fiereza, y aun da el árbol altivo al cielo enojos, forcejando ser nube de sus ojos.

(f. 12 v.)

Los tres meses transcurridos desde el naufragio hasta este momento, según precisa la Relaşão y sigue Corte Real, quedan sugeridos en los siguientes laberinticos versos:

Quatro circulos hizo en claro torno

la luna a la sazón, desde el fracaso do halló sustento el pez, la muerte adorno, y entregó a tierra inculta el débil passo.

(f. 13 r.)

El encuentro con el régulo cafre que los acoge bien y advierte de los peligros que les esperan si siguen adelante, se inicia en el poema portugués al final del canto XI, se desarrolla en el XII y termina en el XIII, mientras que Contreras lo resume en tres octavas (f. I3 v.). De nuevo en marcha, llegan al río deseado, pero en vez de encontrar la nave salvadora, topan con una partida de cafres: "Una quiebra brotó esquadrón adusto / no menos que las picas que sustentan (f. I4 v.); Sepúlveda pide ayuda a un ubárbaro" del escuadrón. Tiene lugar entonces el encuentro con el régulo traidor y astuto. Contreras condensa de tal modo el episodio, que sospecho tiene que resultar muy confuso para quien no conozca el sucedido histórico. Entregadas las armas de

1 Cf., por ejemplo, en el Naufrdgio de Sepuilveda, los cantos VIII-XI, dando de lado, naturalmente, a las digreaiones mitológicas y alegbricas prodigadas por Corte Real en esos cantos, especialmente en el IX, X y XI. 
fuego, dispersos «en distantes albergues», los náufragos son despojados de las cosas de valor que aún poseen ${ }^{1}$. Pero el expolio no ha terminado aún:

La noche triste, toda en vela passaron todos aguardando al dia; vieron calçar a Phebo ardiente espuela, mas con ella picava el alegría. Corre veloz Apolo por su tela, no le impongan el crimen que veía, con todo a un esquadrón dio hachas y luzes, si ya a su rostro dio negros capuces.

$$
\text { (f. I } 5 \text { v.) }
$$

Pocos son ya los supervivientes upues de quinientos que rindió el mar vivos / quedaron veinte y seis solos cautivos» ${ }^{2}$. Estos son quienes sufren el nuevo embate de los cafres, que los despojan de lo único que llevan encima: las ropas. "El negro les robó la presa poca / en que estavan en vida amortajados" (id.). Leonor, pudorosa, resiste en vano a verse desnuda, "cede, y su cuerpo el bárbaro descubre / y sus ojos el sol de empacho cubre» (f. 16 r.). Para esta ocasión, Corte Real dispara de nuevo su batería mitológica:

Tal fica Lianor, qual na montanha troyana a Cytherea foy julgada pollo frígio pastor, e das fermosas três, o preço levou com razão justa.

Assenta-se na branca area e cobre co dourado cabello a lisa carne...

(XVI, f. I9I r. y v.)

La versión de Contreras, limpia de mitologias, aunque no de retórica, me parece más cercana al texto de la Relação. Esta dice: "Hum dos

1 "Porque trazião muitas jóyas e rica pedraria e dinheiro; a affirmão que o que esta companhia trouxe athé alli valia mais de cem mil cruzadosn. Cito, como queda indicado, por la História Trágico-Maritima, I, p. 3I, cuyo texto, salvo el añadido final de origen desconocido (la aventura ulterior de Pantaleão de Sá) es, con levisimas variantes de carácter léxico, igual, por lo menos, al texto de las ediciones del siglo xvir.

- Manoel de Sousa, que com sua mulher e filhos, e com o piloto André Vas e obra de vinte pessoas", ob. cit., p. 3r. 
grandes trabalhos que sentiam [Manuel y Leonor], era verem dous meninos pequenos, seos filhos, diante de si chorando, pedindo de comer, sem the poderem valer. $\mathrm{E}$ vendo-se $\mathrm{D}$. Leonor despida, lançou-se logo no chão e cobrio-se toda com os seos cabellos, que erão muito compridos, fazendo huma cova na area, onde se meteo athé a cintura sem mais se erguer d'alli) (ob. cit., p. 34). Y Contreras:

Atónita, Eleanor clavó los ojos en si y en sus hijuelos casi hiertos; pide al cielo favor, cava la tierra, y como va muriendo, assi se entierra.

Medio cuerpo cubrió en la dura arena, ya pálidos los mármoles más bellos, mas como los mató la vista agena, luego, aunque muertos, se enterraron ellos; al pecho, do qual reyna está su pena, como archeros lo cercan sus cabellos, tales que, en la ocasión, a ser más grata, hallara, émulo el sol, campos de plata.

(f. 16 r.)

En otro punto vuelve a aproximarse Contreras a la Relação, alejándose de Corte Real, quien no hace ninguna referencia a esto. Se trata de las palabras que Leonor, en la situación dicha, dirige a los que están aún en su compañía y les pide que procuren salvarse: «Bem vedes como estamos e que já não podemos passar daqui, e que havemos de acabar, por nossos pecados: hide-vos muito embora, fazey por vos salvar e encomendai-nos a Deos" (ob. cit., pp. 34-35). Y Contreras:

Un partido clavel, mas ya violado, desunió levemente flaco aliento, breve razón formó en fatal estado, y assí a todos habló su sentimiento: "Idos, amigos fieles, ya ha llegado de mi culpa y mi pena el complemento; todo el bien aborrezco, que en amallo ciertas prendas tendré de no alcançallo».

$$
\text { (f. } 16 \text { v.) }
$$

Es entonces cuando Manuel de Sousa, «ainda que estava maltrado do miolo - dice la Relação-, não lhe esquecia a necessidade que sua mulher e filhos passavão de comer", y a pesar de estar herido use foy ao mato buscar frutas para the dar de comer; quando tornou, achou 
D. Leonor muito fraca, assim de fome como de chorar, que depois que os cafres a despirão, nunca mais d'alli se ergueu nem deixou de chorar; e achou hum dos meninos morto, e por sua mão o enterrou na area» (ob. cit., p. 35). Corte Real, por supuesto, lleva a Sepúlveda a la selva en busca de alimentos:

Iintra-se pollo mato; constrangido de dura fome, busca o fructo amargo que a natureza dá por terras secas, estériles, selváticas, bravias.

(XVI, f. I9I v.)

$\mathrm{Y}$ después de una buena tirada de versos a cuenta del amor de Febo por la pobre Leonor, saca a Manuel de la selva:

Chega nesta sazão do bosque umbroso o nobre Souza, e traz monteses fructos que fossem mantimento e sustentassem a vida que $L$ ianor tanto avorrece.

Aos dous pequenos filhos e à companha feminina, reparte o fructo agreste...

$$
\text { (f. } 195 \text { v.) }
$$

Notemos que los dos hijos están vivos, en contra de lo que dice la Relação. Contreras, sin embargo, vuelve a ser fiel a ésta:

Estimulado del infausto aspecto a la selva corrió sin embaraço, por ver si le ofrecia algún concepto de sus entrañas el terrestre braço; truxo algunas raizes, que, a su efecto, les abrevió de su sazón el plaço. Caýda en tierra halló una prenda bella; su juizio es que era de su cielo estrella.

Sin despegar el labio, cava absorto, sirviendo de instrumento débil mano; esconde pío el de la edad aborto, hijo que a luz él dio otro tiempo humano.

(fs. 16 V.-17 r.)

Sepúlveda torna a la selva en busca de más alimentos. Corte Real lo hace perderse en un laberinto de visiones; cuando regresa, Leonor ago- 
niza, muere, y con ella uno de los hijos. Después de recordar la historia de su amor y meditar sobre las mudanzas de la fortuna, Manuel

alevanta-se e vay mudo e choroso onde a praya se ve mais opportuna.

Apartando co as mãos a branca area, abre nella huma estreita sepultura; torna-se atrás, alçando nos cansados braços aquelle corpo lasso e frio.

Ajudão as criadas as funestas derradeiras exéquias con mil gritos.

(XVII, f. 201 V.)

No hay que decir que también es enterrado el hijo muerto. A continuación:

nos braços toma hum filho que alli tinha de tenra idade e vista miserável. Por estreita vereda entra no mato, de bravos leões y tygres povoado; a morte vay buscando, elles, doidos de seu mal, lha darão em breve espaço.

(f. 202 r.)

En efecto; pocos versos más abajo, Corte Real declara atenuadamente que el suicidio ha tenido éxito:

Cobrio-se o espesso bosque de cerrada sombra, fusca nuve, e no circuito que occupava o vapor turvo, se ouvirão de tygres e leões bramidos altos.

(f. 203 v.)

$\mathrm{Y}$ termina con un piadoso «descansar ambos vão na eterna glória». Lo que sigue -los lamentos de Febo, Proteo y Pan por la muerte de doña Leonor- queda ya al margen de nuestro camino.

Es evidente que, en lo esencial, la muerte y entierro de Leonor, Corte Real siguió la versión de la Relação anónima; la siguió también en lo que se refiere al entierro de un hijo, al llanto de las esclavas y a la definitiva pérdida de Sepúlveda en la selva. Pero Corte Real deja vivo, por el momento, al otro hijo, que, como sabemos, ya estaba muerto 
y enterrado. ¿De dónde toma el poeta portugués esta sustancial variante? ¿Es invención suya?

La Relação es parca, pero precisa, como siempre, en este pasaje: "Ao outro dia tornou Manoel de Sousa ao mato a buscar alguma fruta, e quando tornou, achou D. Leonor fallecida, e o outro menino, e sobre ella estavão chorando cinco escravas com grandíssimos gritos. // Dizem que elle não fez mais, quando a viu fallecida, que apartar as escravas d'alli e assentou-se perto della, com o rosto posto sobre huma mão, por espaço de meya hora, sem chorar nem dizer cousa alguma, estando assim com os olhos postos nella; e no menino fez pouca conta. E acabando este espaço se ergueu e começou a fazer huma cova na area com ajuda das escravas; e, sempre sem se falar palavra, a enterrou, e o filho com ella; e acabado isto, tornou a tomar o caminho que fazia quando hia a buscar as frutas, sem dizer nada às escravas, e se meteu pelo mato e nunca mais o virão. Parece que, andando por esses matos - concluye el anónimo--, não há dúvida senão que seria comido de tigres e leons» (ob. cit., pp. 35-36).

Contreras vuelve a mostrarse aquí fiel a este relato, y mientras Manuel de Sousa está por segunda vez en la selva "la Parca infiel da de repente / al alba y su luzero negro velol, es decir, arrebata la vida a Leonor y al hijo que todavía estaba vivo. Regresa Sepúlveda:

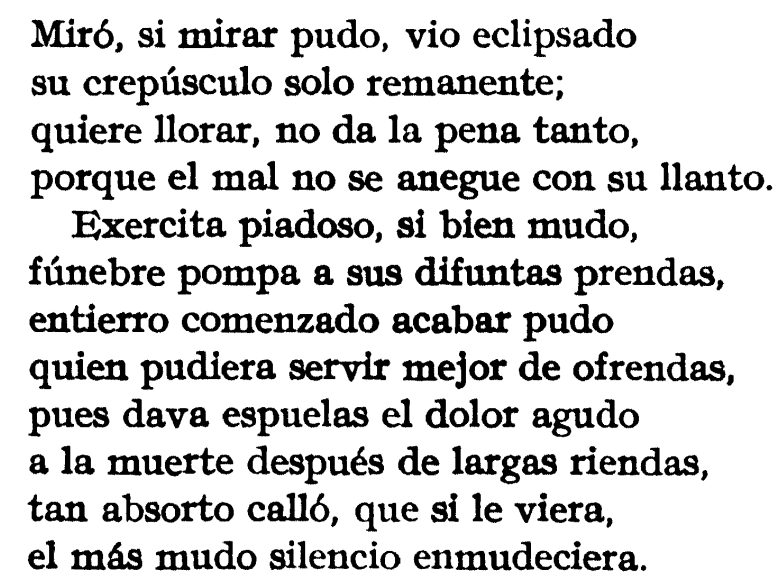

(f. 17 v.)

Notemos que hasta en el pequeño detalle de los ojos enjutos, Contreras está más cerca de la Relação - "o rosto posto sobre huma mão..., sem chorar nem dizer cousa alguman-, que de Corte Real, quien', 'una y otra vez, hace verter copiosas lágrimas al desolado Sepúlveda: «mudo e choroso" y "os olhos com effeito de saudade, / em lágrimas desfaz 
o bulcão turvo" (f. $20 \mathrm{I}$ v.). Contreras hace llorar cultamente al firmamento en dolorosa solidaridad:

Sobre enlutada tumba el alto coro celebra exequias con sus astros bellos, pálida luz y candeleros de oro en tan raro dolor quieren ser ellos; porque iguale la pompa a su decoro, las estrellas desgreñan sus cabellos, pues no puede tal mal llorarlo el suelo, tome a su cargo lamentarlo el cielo.

\section{(f. 18 r.)}

Después, solo, como en la Relação, Manuel de Sousa se pierde en la selva:

Al bosque dirigió su curso al punto, pasmando su desdicha al sentimiento, dibuxando fortuna un fiel trasumpto de su siempre constante movimiento. No pareció; no es mucho, si, difunto, sepulcro en fieras halla, ellas sustento. Musa, pues todo falta, falte el canto, que ya para llorar me falta el llanto.

(f. 18 r.)

Con llanto y una postrera invocación a la Musa trágica, invocada igualmente al final de los cantos I y II, acaba Contreras su relato. Llanto aludido ya en la primera estrofa del poema - «... con sonoro canto / comience, pero acabe en triste acento"-, invocando entonces por primera vez a Melpómene. Ell llanto surge como un leitmotiv todo a lo largo de la Nave trágica.

Al llegar al fin de este trabajo, creo haber dejado claro que Francisco de Contreras leyó el poema de Corte Real; lo leyó y lo aprovechó en la medida en que esto era lícito en su tiempo; pero creo que procedc de la Relação anónima la fidelidad a la verdad histórica que separa a ambos poemas en varios detalles y, en particular, en el desenlace. En cualquier caso, si la Nave trágica de la India de Portugal es más legible por sus dimensiones, el Naufrágio e lastimoso sucesso da perdiçam de Manoel de Sousa de Sepuilveda e Dona Lianor de Sá su molher e filhos etc., es literariamente más valioso, aunque ilegible por su extensión.

José ARes Montes 